Núm. 21-Enero 2020, pp. 79-98

[En línea] http://www.revistas.uma.es/index.php/rejie

\title{
ESTUDIO DEL ACOSO ESCOLAR Y LA RESPONSABILIDAD PENAL DE LOS MENORES AL HILO DE LA PELÍCULA «BULLYING»: UN APRENDIZAJE DEL DERECHO PENAL DE MENORES A TRAVÉS DEL CINE
}

Study of bullying and criminal responsibility of minors at thread of the movie «Bullying»: a learning of the criminal law of minors through the cinema.

Recibido: 21 de mayo de 2019

Aceptado: 28 de octubre de 2019

\author{
Almudena Valiño Ces \\ Profesora de Derecho Procesal \\ Universidad de Santiago de Compostela \\ almudena.valino@usc.es
}

"La educación es el arma más poderosa que puedes utilizar para cambiar el mundo"

Nelson Mandela

\section{RESUMEN}

Desde una perspectiva pro-innovación, la utilización del cine como recurso educativo para el proceso de enseñanza-aprendizaje del Derecho resulta más que común, toda vez que el cine constituye una herramienta muy útil al servicio de los docentes para la impartición de sus materias jurídicas a los estudiantes. Justamente por ello, partimos del visionado de la película «Bullying», que permite analizar y profundizar en la problemática del acoso escolar y la responsabilidad penal que deben asumir los menores por la comisión de este tipo de actos ilícitos.

\section{PALABRAS CLAVES}

Acoso escolar, bullying, justicia penal, responsabilidad penal, menores, recurso educativo, innovación docente.

\section{ABSTRACT}

From a pro-innovation perspective, the use of cinema as an educational resource for the law teachinglearning process is more than common, since cinema is a very useful tool at the service of teachers for the teaching of their legal subjects to the students. Precisely for this reason, we start from the viewing of the film «Bullying», which allows analyzing and deepening the problem of school bullying and the criminal responsibility that minors must assume for the commission of this type of illegal acts.

\section{KEYWORDS}

School bullying, bullying, criminal justice, criminal responsibility, minors, educational resource, teacher innovation. 
Sumario: 1. Introducción. 2. La película «Bullying». 3. Análisis del acoso escolar desde una perspectiva jurídica. 3.1. Aproximación al concepto. 3.2. Tratamiento en la normativa española. 3.3. Estudio de las medidas previstas en la LO 5/2000. 3.4. Soluciones extrajudiciales frente al acoso escolar: creación de programas de mediación en los centros escolares. 3.4.1. Cuestiones generales. 3.4.2. El proceso de normativización de la mediación escolar. 4. El cine como recurso educativo para la explicación del sistema de responsabilidad penal del menor. 5. Conclusiones. Bibliografía.

\section{Introducción.}

Los problemas de acoso escolar o bullying en los centros educativos existen y son, cada vez, más frecuentes. Ello, no obstante, este fenómeno del acoso en las aulas va más allá de lo que sucede en el entorno docente, toda vez que lo que ocurre en los centros escolares es, en numerosas ocasiones, un reflejo de lo que acontece en la vida en todos sus aspectos. Las controversias, la violencia, la conflictividad están en la calle, en la vida doméstica, en el ámbito social, con amigos, con compañeros de actividades extraescolares, en el vecindario. En otras palabras, el acoso puede producirse en todos los ámbitos de la vida, como un fenómeno no solo social, en tanto surge y se desarrolla en un determinado clima de relaciones humanas, que lo potencia, lo permite o lo tolera, sino también psicológico, porque afecta personalmente a los individuos que se ven envueltos en este tipo de problemas ${ }^{1}$.

Por ello, deviene necesario reflexionar acerca de esta problemática desde diferentes perspectivas. Por un lado, en el plano jurídico, a fin de dilucidar la responsabilidad de quien haya podido incurrir en este tipo de conductas y determinar, de ser el caso, si ésta es civil o penal o disciplinaria por un determinado hecho acaecido ${ }^{2}$. Y por otro, en el plano educativo, donde se observa la necesidad de implantar programas de mediación, formar a mediadores para que en este contexto puedan ayudar a resolver, si es posible, esta problemática que se presenta en el día a día y, sobre todo, para prevenir los conflictos que puedan surgir.

\footnotetext{
${ }^{1}$ A juicio de MAGRO SERVET, la escuela es "una de las arenas donde los niños y jóvenes aprenden formas de vincularse, y donde no sólo expanden las experiencias aprendidas a su núcleo familiar, promoviendo conductas fuera de la escuela, sino a su vez condicionan este espacio por las experiencias familiares y vecinales". Así, se entiende que la escuela no se encuentra al margen de la comunidad, por lo que también padece el impacto de lo que sucede habitualmente en la ciudad, en las familias, en los medios de comunicación. Para este autor, la violencia y la inseguridad representan en la actualidad un problema de todos. Por ello, es fundamental no solo realizar un diagnóstico jurídico-social acerca de cómo los jóvenes viven situaciones diarias de violencia, sino también descubrir lo que está pasando, cómo los jóvenes pueden aprender otras vías alternativas para solucionar los conflictos, y en qué medida la ley y la educación han de coordinarse en orden a contribuir a que los jóvenes se responsabilicen de sus comportamientos antisociales y se posicionen racionalmente frente a ciertos fenómenos de acoso desde la empatía y solidaridad con las víctimas de este tipo de comportamientos (MAGRO SERVET, V. (2014), "Otras formas de violencia sobre los menores. El acoso escolar”, La Ley Derecho de familia, 12 de noviembre, Editorial La Ley).

2 PÉREZ MARTELL, R. (2012), "El bullying (acoso escolar) y el cyberbullying: prevención y soluciones desde la vía judicial y las extrajudiciales”, Diario La Ley, núm. 7978, Sección Doctrina, 4 de diciembre, Ref. D-431, Editorial La Ley.
} 


\section{La película «Bullying».}

Desde una perspectiva pro-innovación ${ }^{3}$, la utilización del cine como recurso educativo para el aprendizaje del Derecho resulta más que común, toda vez que el cine constituye una herramienta muy útil, pues la interacción es mutua, en el sentido de que el cine se ocupa del Derecho y el Derecho tiene también el cine como objetivo 4 . Tanto es así que muchos argumentos cinematográficos tienen como trama principal asuntos jurídicos.

Asimismo, la introducción del cine como recurso docente aplicado a la enseñanza del Derecho proporciona elevados resultados de aprendizaje. Se considera que resulta más sencillo captar la atención del alumnado con la proyección de una película que con una exposición de diapositivas repletas de esquemas y comentarios escritos. Y ello porque, en un ámbito como el jurídico, caracterizado por una vertiente teórica muy clara, sin duda, los códigos y los manuales prevalecen como herramienta básica para el estudio de cualquier materia, pero el estudio de instituciones, principios y conceptos jurídicos mediante películas conlleva un paso más en el desarrollo de nuevas metodologías, que favorecen el aprendizaje completo a través de la aplicación práctica ${ }^{5}$. Por tal motivo, es fácil comprender que el cine jurídico se haya convertido en objeto de investigación y en instrumento para la docencia.

Justamente por ello, partimos del visionado de la película «Bullying» ${ }^{6}$, que permite analizar y profundizar en la problemática del acoso escolar, a fin de darle una vuelta de tuerca al recurso mencionado para optimizar sus posibilidades a la hora de la enseñanzaaprendizaje e incrementar, así, la capacidad de estimulación del alumnado. Ahora bien, cuando el cine se integra en el seno de determinadas asignaturas del Grado en Derecho o del Grado de Criminología, debe complementarlas o combinarse con otras formas de enseñanza, no sustituirlas.

\footnotetext{
${ }^{3} \mathrm{Al}$ aludir a la innovación, en tanto constituye una actividad inherente a la propia docencia, nos referimos a un proceso que implica la introducción de cambios que producen mejora, cambios que responden a un proceso planeado, deliberado, sistematizado e intencional. Por tanto, no nos encontramos ante una cuestión casual o espontánea, sino intencional e impulsada voluntariamente (CASAL OTERO, L. (2019), "La innovación educativa en la educación superior", en OTERO CRESPO, M., ALONSO SALGADO, C. (Dirs.), VALIÑO CES, A. Y RODRÍGUEZ ÁLVAREZ, A. (Coords.), Investigación y Docencia en Derecho: nuevas perspectivas. A Coruña: Colex, p. 19).

${ }^{4}$ En este sentido, cabe destacar tres posibles perspectivas del movimiento Derecho y Cine. En primer lugar, el Derecho en el Cine, en tanto se ocupa de analizar la presencia del fenómeno jurídico en las películas, esto es, pone el acento en el tratamiento cinematográfico de cuestiones, problemas o situaciones con relevancia jurídica; en segundo lugar, el Derecho como Cine, en cuyo caso se encargaría del Derecho como drama y, por ende, fundamentalmente de los aspectos de dramatización propios del Derecho, sobre todo del proceso; y en tercer lugar, el Derecho del Cine, también denominado Derecho cinematográfico y que está formado por las normas jurídicas que regulan en sus diversos aspectos el fenómeno cinematográfico. Se trata de un estudio temático de derecho positivo que comprende los diferentes sectores del ordenamiento jurídico -constitucional, civil, penal, administrativo, mercantil, etc.-, así como las correspondientes resoluciones judiciales y trabajos doctrinales. A fin de profundizar en estas tres perspectivas, véase: PRESNO LINERA, M. A. y RIVAYA, B. (2006), Una introducción cinematográfica al Derecho. Valencia: Tirant lo Blanch, pp. 17 a 19.

5 ÁLVAREZ GONZÁLEZ, E. M. (2015), "El cine como recurso docente aplicable a la enseñanza del derecho administrativo", REJIE: Revista Jurídica de Investigación e Innovación Educativa, núm. 11, enero, pp. 98 y 99 .

${ }^{6}$ A fin de conocer la ficha técnico-artística de la película, véase VALIÑO CES, A. (2018), "Material didáctico sobre la película «Bullying»", Revista electrónica Proyecto DeCine, 12 de noviembre. Disponible en https://proyectodecine.wordpress.com/2018/11/12/materia-didactico-abierto-bullying/.
} 
Este filme narra la historia de Jordi, un adolescente de 15 años que ha perdido recientemente a su padre y que, junto con su madre, decide cambiar de ciudad para iniciar una nueva vida. Al principio todo parece ir bien, pero el destino le reserva una terrible sorpresa, pues cuando traspasa las puertas de su nuevo instituto, cruza sin saberlo la tenebrosa frontera del mismísimo infierno. Y quien le invita a entrar en él, es Nacho, un compañero de clase que, a pesar de su edad, pertenece a la raza de los que se alimentan únicamente del miedo y del dolor ajeno. Nacho será capaz de lograr que, en la pesadilla que sumerge a Jordi, cada día que pase sea superado en violencia y crueldad por el siguiente. Frente a esta situación, y tratando de encontrar una salida desesperadamente, Jordi emprenderá un aterrador viaje en el que experimentará en primera persona lo que es la humillación, la maldad, el miedo, la violencia y el pánico y en el que los enemigos serán sus propios compañeros de clase.

En esta búsqueda desesperada, las personas que acompañarán a nuestro protagonista serán, por un lado, Julia, una madre confundida que no logra entender lo que ocurre y que se presenta como un oscuro y misterioso personaje que carga con un secreto del pasado, y por otro, Annia, una chica capaz de comprender a Jordi, porque ella también conoce los mil rostros del horror. Un viaje cuyo término será decidido en una reacción final por el propio Jordi, quien como cualquier ser humano tiene en la libertad una meta vital indispensable.

«Bullying» es, sobre todo, una película que incita a la reflexión sobre la actual regulación del sistema penal de los menores. Son muchos los mensajes que transmite, entre los que cobran especial importancia los actos llevados a cabo por menores y sus consecuencias jurídicas ${ }^{7}$. Y ello porque la palabra bullying se ha hecho tristemente conocida en los medios de comunicación para designar los casos de acoso escolar y éste es precisamente el tema central que aborda la película.

Con todo, el leitmotiv de este filme se complementa, desde la óptica jurídica, con el tema de la responsabilidad penal que deben asumir los mayores de catorce años y menores de dieciocho por la comisión de ilícitos penales contemplados en el Código Penal y en las restantes leyes penales especiales, siempre que no concurra en ellos ninguna de las causas de exención de la responsabilidad criminal previstas en esta norma. En concreto, una responsabilidad que conllevará unas consecuencias y que se encuentra expresamente regulada en la Ley Orgánica 5/2000, de 12 de enero, reguladora de la responsabilidad penal de los menores ${ }^{8}$. Esta Ley contiene normas específicas y un procedimiento especial

\footnotetext{
${ }^{7}$ Entre las lecturas recomendadas a este respecto, cabe destacar: RODRÍGUEZ AMUNÁTEGUI, C. (2007), La responsabilidad civil derivada del bullying y otros delitos de los menores de edad. Madrid: Ediciones del Laberinto, S.L.; MONTERO HERNANZ, T. y DE VICENTE MARTÍNEZ, R. (2016), Derechos de las personas a las que se aplique la ley orgánica reguladora de la responsabilidad penal de los menores. Valencia: Tirant lo Blanch; ZABAY, M. y CASADO, A. (2018), Todos contra el bullying. Claves para detectar, evitar y solucionar el acoso escolar. Barcelona: Alienta Editorial; o JIMÉNEZ DÍAZ, M. J. (2015), "Algunas reflexiones sobre la responsabilidad penal de los menores", Revista Electrónica de Ciencia Penal y Criminología (en línea), núm. 17-19, pp. 1-36.

${ }^{8}$ En adelante, LO 5/2000.

El 13 de enero de 2001 entró en vigor esta Ley y desde entonces ha sido objeto de numerosas reformas, intentándose adaptar a los cambios que han tenido lugar en la sociedad, introduciéndose dos novedades: establece por primera vez términos como la responsabilidad civil del menor y la responsabilidad civil solidaria - con la finalidad de reparar el daño a la víctima- e impone un régimen específico para todos los mayores de 14 y menores de 18 que cometan un delito.

Lo cierto es que el objetivo principal de esta Ley no es el de imponer penas a los infractores, sino más bien medidas destinadas a la reeducación que logren la total reinserción del menor en la sociedad.
} 
para el enjuiciamiento de los menores, diferentes a las contempladas en el Código Penal ${ }^{9}$ y en la Ley de Enjuiciamiento Criminal ${ }^{10}$ para el enjuiciamiento de los mayores de edad ${ }^{11}$.

\section{Análisis del acoso escolar desde una perspectiva jurídica.}

\subsection{Aproximación al concepto.}

La violencia escolar, en sus distintas manifestaciones, ha adquirido un especial protagonismo en los últimos años. A ello ha favorecido el notable incremento de las agresiones o actos violentos en nuestros centros educativos, perturbando su normal desarrollo y generando cierta alarma en la sociedad o, cuanto menos, un gran reproche social por la perversidad o nula sensibilidad que el agresor o agresores vienen a experimentar en la producción de los daños.

Sin perjuicio de que estos actos violentos se proyectan en diversos ámbitos, lo cierto es que donde mayor incidencia está adquiriendo la violencia es en las agresiones -tanto físicas como psicológicas - entre compañeros, que la mayoría de las veces son grabadas en el móvil y difundidas por Internet, constituyendo el fenómeno conocido como acoso escolar, maltrato entre iguales o bullying ${ }^{12}$.

Este fenómeno del acoso escolar, de acuerdo con la Real Academia española, es definido como el acoso que uno o varios alumnos, en centros de enseñanza, ejercen sobre otro con el fin de denigrarlo y vejarlo ante los demás, lo que puede provocar su exclusión social. En consecuencia, se entiende que existe acoso escolar cuando hay una conducta de maltrato físico, psicológico o verbal de un escolar a otro, de una forma reiterada y en una situación de superioridad. Por lo que el elemento que diferencia el acoso escolar de un conflicto puntual entre escolares es la repetición en el tiempo, de manera tal que lo que al final sucede es una situación de daño físico y psicológico al menor.

Al hilo de esta idea, es numerosa la doctrina que se pronuncia acerca del concepto de acoso escolar. Así, FERRO VEIGA entiende que se trata de "cualquier forma de maltrato psicológico, verbal o físico, producido entre escolares de forma reiterada a lo largo de un tiempo determinado" "13. Por su parte, RODRÍGUEZ AMUNÁTEGUI señala que se pueden integrar dentro del acoso escolar las conductas de agresión física, psicológica o moral de un grupo de alumnos sobre otro u otros ${ }^{14}$. GONZÁLEZ PÉREZ y SANTIUSTE BERMEJO consideran que "un alumno es agredido o se convierte en víctima cuando está expuesto, de forma repetida y durante un tiempo, a acciones negativas que lleva a cabo

\footnotetext{
${ }^{9}$ En adelante, $\mathrm{CP}$.

${ }^{10}$ En adelante, LECrim.

11 En este sentido, cabe destacar que la naturaleza de la ley es penal, aunque su objetivo último sea sancionador o educativo. Por naturaleza penal nos referimos, al igual que ocurre en los adultos, a que la ley castiga los delitos y bajo su regulación se celebran juicios con fiscal y abogado defensor en los que se impone una pena. Lo único que diferenciaría a esta ley es que con ella no se pretende únicamente castigar, sino más bien reeducar, fomentar el buen desarrollo y prevenir que el delincuente juvenil cometa más delitos en el futuro.

12 BERROCAL LANZAROT, A. I. (2010), "La comunidad educativa ante el acoso escolar o bullying. La responsabilidad civil de los centros docentes”, Diario La Ley, núm. 7359, año XXXI, 10 de marzo, Ref. D79, Editorial La Ley.

${ }^{13}$ FERRO VEIGA, J. M. (2012), Bulling o acoso escolar. La respuesta jurídico-legal. Jaén: Formación Alcalá, p. 9.

${ }^{14}$ RODRÍGUEZ AMUNÁTEGUI, C. (2007), La responsabilidad civil derivada del bullying y otros delitos de los menores de edad..., op. cit., p. 65.
} 
otro alumno o varios de ellos"15. De igual modo, para PÉREZ MACHÍO, el bullying consiste en un tipo de acoso moral circunscrito al ámbito escolar que aun cuando comparte con el mobbing varios de los elementos sustantivos, nada tiene que ver con el mundo del trabajo ${ }^{16}$. En la misma línea, CASTILLEJO MANZANARES lo concibe como actos repetidos, por parte de uno o más alumnos, de intimidación y acoso, como son insultos, motes, vejaciones, aislamiento social, rumores a otro -la víctima-. A su juicio, el maltrato puede ser: físico, a través de empujones, patadas, puñetazos, etc.; verbal, se expresa por medio de insultos, motes, humillaciones públicas, burlas acerca de algún defecto real o imaginado, etc.; psicológico, este componente está presente en todas las modalidades de maltrato y genera temor en la víctima; o social, se trata de aislar o desprestigiar a la víctima, rompiendo o debilitando su nexo de unión con el entorno social, dejándola sola $\mathrm{y}$, por tanto, indefensa ${ }^{17}$.

Habida cuenta de lo acabado de exponer, POLVOROSA ROMERO entiende que los elementos que definen el acoso escolar son, en primer lugar, la continuidad en el tiempo, pues para que la conducta sea considerada como tal debe ser reiterada ${ }^{18}$, generando en el menor acosado una situación de ansiedad y miedo de que se vuelva a repetir; en segundo lugar, la intencionalidad que suele existir en herir o dañar a la otra parte, aunque en ocasiones, y sobre todo cuando ese acoso se da entre niños pequeños, este punto puede ser cuestionado, ya que simplemente el motivo del acoso puede ser querer conseguir una situación de liderazgo sobre los compañeros por parte del menor acosador; y en tercer lugar, la superioridad, bien porque el menor acosador sea mayor por edad, por condiciones físicas, por realizar ese hostigamiento en grupo, etc ${ }^{19}$.

Asimismo, es numerosa la jurisprudencia que define lo que se entiende por acoso escolar o bullying. A modo de ejemplo, la Sala de lo Contencioso-Administrativo, Sección 4ª del Tribunal Superior de Justicia de Cataluña, en su sentencia núm. 960/2009, de 3 de diciembre, lo califica como "cualquier forma o conjunto de actividades agresivas, intencionadas y repetidas que ocurren sin motivación evidente, adoptadas por uno o más

15 GONZÁlEZ PÉREZ, J. y SANTIUSTE BERMEJO, V. (2004), "Los conflictos entre alumnos: características e intervención para una sociedad democrática", Revista de Psicología General y Aplicada, núm. 57 (3), p. 362.

${ }^{16}$ PÉREZ MACHÍO, A. I. (2007), "Tratamento xurídico-penal do bullying”, en XUNTA DE GALICIA, Menores e xuventude: novos retos. Cambados (Pontevedra): Consellería de Presidencia, Academia Gallega de Seguridad Pública, p. 45.

${ }^{17}$ También alude al ciberbullying, en tanto consiste en el uso de los medios telemáticos (internet, telefonía móvil y videojuegos online principalmente) para ejercer el acoso psicológico entre iguales. A este respecto, es preciso que haya menores en ambos extremos del ataque para que se considere ciberbullying (CASTILLEJO MANZANARES, C. (2017), "La mediación en el ámbito educativo", en CASTILLEJO MANZANARES, R. (Dir.), ALONSO SALGADO, C. y VALIÑO CES, A. (Coords.), La mediación a examen: experiencias innovadoras y pluralidad de enfoques. Santiago de Compostela: Servicio de Publicaciones e Intercambio Científico de la Universidad de Santiago de Compostela, p. 307).

${ }^{18}$ La exigencia de, al menos, una cierta repetición de los actos de agresión, se vincula a la necesidad de que estos sean susceptibles de quebrantar la resistencia física o moral de la víctima, dado que un hecho violento puntual, no resulta suficiente para ocasionar el desmoronamiento de la persona, característico del acoso. Así pues, una agresión aislada podría generar la responsabilidad patrimonial de la Administración, pero no parece que pudiera calificarse como un caso de acoso escolar (FRANCO GARCÍA, M. A. (2016), "Los nuevos criterios atributivos de responsabilidad patrimonial en el acoso escolar entre alumnos", Actualidad administrativa, núm. 4).

${ }^{19}$ Una situación que normalmente no se califica como acoso escolar, pero es una de las formas más crueles de acoso, son los rumores, los chismes, cuyo fin es destruir la reputación del menor acosado y lograr con ello su aislamiento. Y en este punto las redes sociales, los grupos de whatsapp, es decir, el acceso que están teniendo los menores a Internet, están jugando un papel crucial (POLVOROSA ROMERO, S. (2017), "El acoso escolar llevado a internet: los smartphone y smartwatch”, La Ley Derecho de familia, núm. 14). 
estudiantes contra otro u otros. El que ejerce el bullying lo hace para imponer su poder sobre el otro, a través de constantes amenazas, insultos, agresiones, vejaciones, etc., y así tenerlo bajo su completo dominio a lo largo de meses e incluso años. Pero esta conducta, constitutiva de gran alarma social no puede tampoco estimarse a la ligera, debe ser objeto de un minucioso seguimiento, control, diagnóstico y signos evidentes de su presencia por el entorno". Por su parte, la sentencia de la Audiencia Provincial de Ourense núm. 147/2017, de 21 de abril, sostiene que el acoso escolar "requiere para poder definirse como tal, según autorizada definición doctrinal, una serie de actos o incidentes intencionales, de naturaleza violenta -constitutivos de agresión física o psíquica y caracterizada por su continuidad en el tiempo-dirigidos a quebrantar la resistencia fisica o moral de otro alumno, que tienen lugar entre alumnos menores de edad, cuando se hallan éstos bajo la vigilancia y guarda de un centro educativo".

Desde una perspectiva legislativa, y a modo de ejemplo, la Ley 4/2011, de 30 de junio, de convivencia y participación de la comunidad educativa de Galicia, en su artículo 28 , define el acoso escolar en los siguientes términos: "A los efectos de la presente ley, se considera acoso escolar cualquier forma de vejación o malos tratos continuados en el tiempo de un alumno o alumna por otro u otra u otros, ya sea de carácter verbal, físico o psicológico, incluido el aislamiento o vacio social, con independencia del lugar donde se produjese. Tendrán la misma consideración las conductas realizadas a través de medios electrónicos, telemáticos o tecnológicos que tuvieran causa en una relación que surja en el ámbito escolar".

\subsection{Tratamiento en la normativa española.}

El acoso escolar no constituye un fenómeno nuevo, sino que lleva ocurriendo desde hace décadas. Sin embargo, no es hasta 1970 cuando algunos estados comienzan a dar la voz de alarma acerca de la grave problemática que están sufriendo algunos alumnos. Tomando como punto de partida la Declaración de los Derechos del Niño de 1959 y la Convención de los Derechos del Niño de 1989, algunos países como Suecia, Noruega, Francia, Alemania, Inglaterra o Estados Unidos empezaron a desarrollar leyes para proteger a sus menores del fenómeno del bullying. Y ello porque los estados se plantearon que debían buscar activamente una solución a estos problemas, puesto que, si todos los delitos de violencia deben ser combatidos, en los casos de acoso escolar el celo debe ser aún mayor, dada la especial vulnerabilidad de los menores y los graves efectos de la violencia en la formación de la personalidad y en la sociabilidad del niño ${ }^{20}$.

Por lo que respecta a nuestro país ${ }^{21}$, cabe referirse a la LO 5/2000, en tanto su artículo 1.1 señala que "esta Ley se aplicará para exigir la responsabilidad de las personas

\footnotetext{
${ }^{20}$ Por ello, el Parlamento Europeo aprobó un programa de acción comunitaria, el Programa DAPHNE III de medidas preventivas para combatir la violencia ejercida sobre los niños, adolescentes y mujeres, integrado en el programa general Derechos fundamentales y Justicia (2007-2013) contra la violencia ejercida sobre la infancia, los jóvenes y las mujeres. Este programa incluye la sensibilización a través de la educación, aspectos preventivos, educativos, sociales, asistenciales y de atención a las víctimas.

${ }^{21}$ En España, la alarma social no se desató hasta el trágico suicidio de Jokin, en el año 2004, que, desesperado por el hostigamiento que sufría diariamente en su centro escolar, decidió quitarse la vida. Desde ese momento, la sociedad española comenzó a preocuparse por lo que sucedía en los colegios, por el papel de los padres, el profesorado, las direcciones de los centros escolares, etc. Muchas personas se percataron de que los casos de acoso escolar no podían reducirse a bromas, peleas entre iguales o conflictos puntuales, sino que se trataba de un problema grave de abuso hacia el más débil, que podía compararse en importancia a la violencia de género. A pesar de que la sociedad estaba más comprometida y de que algunas sentencias impusieron castigos ejemplarizantes (en el caso de Jokin, los menores implicados fueron condenados a dos años de internamiento en un centro de menores y sus padres fueron sancionados con
} 
mayores de catorce años y menores de dieciocho por la comisión de hechos tipificados como delitos o faltas en el Código Penal o las leyes penales especiales". No existe, por tanto, un tipo específico de delito de acoso. De tal forma que será necesario acudir al Código Penal para su tipificación. Al respecto, señala la Instrucción 10/2005 de la Fiscalía General del Estado que "si se sigue la definición amplia de acoso escolar que suele emplear psiquiatras, psicólogos y pedagogos (exposición de un alumno, de forma repetida y durante un tiempo, a acciones negativas que lleva a cabo otro u otros alumnos) no existe una traducción jurídico penal unitaria de estos comportamientos. Las tonalidades más o menos intensas que estas conductas violentas, intimidatorias o denigratorias pueden alcanzar, pueden plasmarse en una amplia gama cromática no susceptibles de reduccionismos o simplificaciones. Debe, por tanto, partirse de que el concepto de acoso escolar es metajurídico, pudiendo tener diversas significaciones jurídicas penales, desde la mera falta a la comisión de un delito grave. Habrá de estarse en cada supuesto a los hechos como paso previo a la operación de subsunción penal'.

En consecuencia, el Código Penal no tipifica el delito de acoso escolar, por lo que los hechos han de reconducirse a la posible existencia de otros delitos. Ahora bien, ha de tenerse en cuenta que, tras la entrada en vigor de la LO 5/2000, modificada por la Ley Orgánica $8 / 2006$, de 4 de diciembre, se eleva la mayoría de edad penal a los dieciocho años $^{22}$. Así, los menores de esa edad podrían ser responsables con arreglo a la Ley que regula la responsabilidad penal del menor. Esta Ley se aplicará para exigir la responsabilidad de las personas mayores de catorce años y menores de dieciocho por la comisión de los hechos tipificados como delitos o faltas (actualmente sólo como delitos ${ }^{23}$ ) en el Código Penal o en Leyes penales especiales -artículo 1.1 de la citada Ley Orgánica-. Cuando el autor de los hechos mencionados en los preceptos anteriores sea menor de catorce años no se le exigirá responsabilidad con arreglo a la presente Ley, sino que se aplicará lo dispuesto en las normas sobre protección del menor previstas en el Código Civil y demás disposiciones vigentes ${ }^{24}$.

multas de 10.000 euros), el número de denuncias por bullying en nuestro país sigue aumentando. Alguna de las razones de este incremento puede ser la escasa implicación de algunos centros escolares en el problema, toda vez que tratan de minimizarlo o ignorarlo para no perjudicar su imagen, y además en nuestro país, si los agresores son menores de 14 años, se entiende que sus actos no son constitutivos de delito y, por consiguiente, no son punibles.

${ }^{22}$ Con la entrada en vigor de la LO 5/2000 se puso fin a la problemática existente en torno a la franja de edad de los ciudadanos comprendidos entre los 14 y los 18 años, pudiendo, a partir de ese momento, ser considerados y, por ende, juzgados, como lo que realmente son: menores de edad, con todas las obligaciones que se les exigen, pero también con el respeto a todos sus derechos inherentes como personas y que legalmente tienen reconocidos en todos los ámbitos que les afectan. Ahora bien, las edades deben entenderse siempre referidas al momento de la comisión de los hechos, sin que tenga repercusión alguna superar las mismas antes de empezar el procedimiento o durante su tramitación.

${ }^{23}$ Recordemos que desde el 1 de julio del 2015, las faltas han desaparecido del CP español de acuerdo con la reforma operada por Ley Orgánica 1/2015, de 30 de marzo, por la que se modifica la Ley Orgánica 10/1995, de 23 de noviembre, del Código Penal.

${ }^{24}$ A los menores de 14 años no se les puede aplicar esta Ley, por lo que deberán ser puestos a disposición de las instituciones administrativas de protección de menores. En estos casos, el Ministerio Fiscal debe remitir testimonio de particulares a la entidad pública de protección competente, a fin de que aplique las medidas tuitivas o de protección correspondientes (artículo 3.1 de la LO 5/2000 en relación con la Ley Orgánica 1/1996, de 15 de enero, de Protección Jurídica del Menor, de modificación parcial del Código Civil y de la Ley de Enjuiciamiento Civil). 
Más allá de otros posibles hechos delictivos que pudieran colegirse ${ }^{25}$, cabe resaltar el estudio del artículo 173.1 del Código Penal $^{26}$, por ser el delito que se debe aplicar generalmente en el caso que nos ocupa, en relación con la citada LO 5/2000, por tratarse de agresores menores de edad. En concreto, el tipo penal definido pertenece a los delitos contra la integridad moral cuyo bien jurídico protegido es el derecho a la inviolabilidad de la personalidad humana. La acción típica de esta conducta delictiva consiste en infligir a otra persona, en el caso de la película a Jordi, un trato degradante menoscabando gravemente su integridad o dignidad moral.

En este delito, de carácter genérico, se tipifican aquellos comportamientos que conlleven un atentado contra la integridad física, que tengan un efecto inmediato sobre su esfera corporal y que, además, supongan la sumisión de la víctima a ciertas condiciones que impliquen una humillación grave. Nos encontramos ante un tipo residual que se aplica cuando la conducta no es subsumible en otro tipo delictivo o que, aun siéndolo, dicho tipo no es suficiente para castigar el aspecto denigrante de esa conducta. Así, es posible castigar al amparo de este precepto conductas producidas a lo largo de la película, como las de obligarle a beber alcohol o a fumar, apuntarle con un arma o echarle laxante en la bebida.

En otro orden de cosas, y al hilo de lo expuesto, cabe resaltar que para iniciar el procedimiento que enjuicie la responsabilidad de los menores por sus actos, se necesita la denuncia de quien tuviera noticia de algún hecho delictivo o la detención por parte de un funcionario de la policía. En este caso, no existe ninguno de ellos, nadie es consciente de la existencia del acoso, ningún compañero lo reconoce o, si lo hacen, califican esa conducta de "bromitas" o "chorraditas". Incluso, Jordi lo niega en todo momento ("no me pasa nada, simplemente soy asi"), miente para justificar su apatía, su estado de embriaguez ("lo hacen todos los niños de mi edad"). Por su parte, la directora no sólo afirma que en su colegio no se producen esas agresiones porque existen protocolos contra este tipo de conductas, sino que, ante el reproche de la madre, aquélla le responsabiliza de todo, "que no se entera de lo que sucede en su casa" y la califica de "pobre histérica".

\footnotetext{
${ }^{25}$ A este respecto, FRANCO GARCÍA señala que en el epicentro del concepto de acoso escolar, se encuentra la afectación a distintos derechos fundamentales del acosado, protegidos constitucionalmente, como el derecho a la intimidad personal, al honor o a la propia imagen (artículo 18.1), la dignidad de la persona (artículo 10.1) y el derecho a su integridad física y moral (artículo 15), reconociéndose explícitamente los dos últimos citados. Por lo que se refiere a la esfera educativa, en el artículo 6.3.b) de la Ley Orgánica 8/1985, de 3 de julio, que regula el Derecho a la Educación, se determina que todos los alumnos tienen el derecho básico a que "a que se respeten su identidad, integridad y dignidad personales". Así, la existencia de una pluralidad de agresiones, es decir, su reiteración y continuidad en el tiempo, se alza también como una característica necesaria para distinguir el acoso escolar de los incidentes violentos, aislados u ocasionales entre alumnos o estudiantes (FRANCO GARCÍA, M. A. (2016), "Los nuevos criterios atributivos de responsabilidad patrimonial en el acoso escolar entre alumnos"...,op. cit.).

${ }^{26}$ Este precepto prevé: "1. El que infligiera a otra persona un trato degradante, menoscabando gravemente su integridad moral, será castigado con la pena de prisión de seis meses a dos años.

Con la misma pena serán castigados los que, en el ámbito de cualquier relación laboral o funcionarial y prevaliéndose de su relación de superioridad, realicen contra otro de forma reiterada actos hostiles o humillantes que, sin llegar a constituir trato degradante, supongan grave acoso contra la víctima.

Se impondrá también la misma pena al que de forma reiterada lleve a cabo actos hostiles o humillantes que, sin llegar a constituir trato degradante, tengan por objeto impedir el legítimo disfrute de la vivienda". La sentencia del Tribunal Supremo núm. 819/2002, de 8 mayo, señala que el delito del artículo 173 representa el tipo básico de las conductas incluidas dentro del Título VII del Libro II del Código Penal, como delitos contra la integridad moral de las personas; requiriendo para su apreciación de la concurrencia de un elemento medial -"infligir a una persona un trato degradante"-, y un resultado -"menoscabando gravemente su integridad moral"-.
} 
En estos casos, si se hubiesen denunciado los hechos, sería el juez de menores el encargado de pronunciarse sobre la responsabilidad penal derivada de los hechos cometidos por estos menores, de la responsabilidad civil de los mismos, así como de velar por el cumplimiento y la ejecución de sus sentencias. En relación con esto, el Ministerio Fiscal debe velar por el respeto de los derechos que legalmente se reconocen a los menores de edad.

\subsection{Estudio de las medidas previstas en la LO 5/2000.}

El rasgo característico y primordial del Derecho penal de menores es la intervención educativa. Por ello, las medidas tienen una finalidad esencialmente de prevención especial, de carácter positivo integrador y educativo, no represivo, orientadas a la reinserción del menor.

En este sentido, al tratarse de menores, no se le impondrán penas -de multa, de localización permanente o de prisión-, sino que deberán cumplir unas medidas correctoras dirigidas a su rehabilitación, con la finalidad de que salden sus responsabilidades y abandonen los malos hábitos que los han llevado a cometer infracciones. Estas medidas pueden ser de diversos tipos y comprenden desde la amonestación hasta el internamiento en régimen cerrado. En este sentido, y en el marco de la película referida, se observa que a pesar de la ayuda de Bruno -el vecino- y Annia, por acabar con la situación de acoso que sufre el protagonista, no se adopta ningún tipo de medida ante los hechos perpetrados, sobre todo por Nacho, lo que sin duda provocará el trágico final para Jordi. Un final que tristemente representa la causa número uno de muertes no naturales en nuestro país.

La Ley establece un amplio catálogo de medidas aplicables, desde la referida perspectiva sancionadora-educativa, debiendo prevalecer nuevamente el interés del menor en la flexible adopción judicial de la medida más adecuada, dadas las características del caso concreto y de la evolución personal del sancionado durante la ejecución de la medida. En concreto, la Ley establece actualmente un catálogo de medidas que pueden clasificarse someramente en medidas privativas de libertad, medidas no privativas de libertad y medidas terapéuticas.

En primer lugar, las medidas privativas de libertad se refieren al internamiento en régimen cerrado, en régimen semiabierto y régimen abierto. Los menores sometidos al internamiento en régimen abierto residirán en el centro y desarrollarán en el mismo las actividades formativas, educativas, laborales y de ocio. Al igual que en el caso anterior, en el internamiento en régimen semiabierto los menores también residirán en el centro. Ello, no obstante, estos podrán realizar fuera del mismo alguna o algunas de las actividades formativas, educativas, laborales y de ocio determinadas en el programa individualizado de ejecución de la medida. La realización de actividades fuera del centro quedará supeditada a la evolución de la persona y al cumplimiento de los objetivos previstos en las mismas, pudiendo el juez de menores suspenderlas por tiempo determinado, acordando que todas las actividades se desarrollen dentro del centro. Por último, los menores internados en régimen abierto llevarán a cabo todas las actividades en los servicios normalizados del entorno, residiendo en el centro como domicilio habitual, con sujeción al programa y régimen interno del mismo.

Estas medidas persiguen la adquisición por parte del menor de los suficientes recursos de competencia social para permitir un comportamiento responsable en la comunidad, a través de una gestión de control en un ambiente restrictivo y autónomo. En definitiva, en 
estos casos, los menores residen en un centro y sus salidas al exterior pasan de ser nulas a ser habituales en función del régimen de internamiento.

En segundo lugar, las medidas terapéuticas son el internamiento y el tratamiento terapéuticos que están dirigidas a menores que sufren deficiencias, anomalías, adicción a determinadas sustancias y que precisan tratamiento. La primera de ellas implica una medida más restrictiva, toda vez que supone el internamiento -en régimen cerrado, semiabierto o abierto-, mientras que la segunda consiste en acudir al centro con cierta periodicidad.

Respecto a la primera de ellas, cabe exponer que en los centros donde se realice el internamiento, se llevará a cabo una atención educativa especializada o tratamiento específico dirigido a menores que padezcan anomalías o alteraciones psíquicas, un estado de dependencia de bebidas alcohólicas, drogas tóxicas o sustancias psicotrópicas, o alteraciones en la percepción que determinen una alteración grave de la conciencia de la realidad. Esta medida podrá aplicarse sola o como complemento de otra medida de las previstas. Cuando el interesado rechace un tratamiento de deshabituación, el juez deberá de aplicarle otra medida adecuada a sus circunstancias.

Por otra parte, con relación al tratamiento ambulatorio, es preciso señalar que los menores sometidos a esta medida deberán de asistir al centro designado con la periodicidad determinada por los facultativos que las atiendan y seguir las pautas establecidas para el correcto tratamiento de la anomalía o alteración psíquica, adicción al consumo de bebidas alcohólicas, drogas tóxicas o sustancias psicotrópicas, o alteraciones en la percepción que padezcan.

En ambos casos se trata de una medida que podrá aplicarse sola o como complemento de otra de las medidas previstas. Y en caso de que el interesado rechace un tratamiento de deshabituación, el juez habrá de aplicarle otra medida adecuada a sus circunstancias.

Por último, en cuanto a las medidas no privativas de libertad son las más numerosas y podemos clasificarlas del siguiente modo.

La permanencia de fin de semana ${ }^{27}$ en el propio domicilio o en un centro durante un máximo de 36 horas entre la tarde del viernes y la noche del domingo, con la excepción, en su caso, del tiempo necesario para desarrollar las tareas socio-educativas asignadas por el juez, que deban realizarse fuera del lugar de permanencia. Esta medida resulta adecuada para menores que cometen actos de vandalismo o agresiones leves en los fines de semana.

La libertad vigilada conlleva la vigilancia y supervisión del menor por el profesional nombrado, efectuando un seguimiento de su actividad y su asistencia a la escuela ${ }^{28}$, al centro de formación profesional o al lugar de trabajo, en función de los casos, tratando de ayudar a aquél a superar los factores que determinaron la infracción cometida. De igual modo, esta medida constriñe, en su caso, a seguir las pautas socio-educativas que determine la entidad pública o el profesional encargado de su seguimiento, de conformidad con el programa de intervención elaborado al efecto y aprobado por el juez de menores. El menor sometido a la medida también queda obligado a mantener con el citado profesional las entrevistas previstas en el programa y a acatar las reglas de conducta

\footnotetext{
27 También puede ser calificada como medida privativa de libertad.

${ }^{28}$ En este caso, debe entrevistarse con el supervisor y acatar las reglas de conducta que hayan sido impuestas por el juez, como no acudir a determinados lugares, comparecer en el juzgado, etc. Puede ser autónoma, principal, accesoria o el segundo periodo de cumplimiento de una medida de internamiento.
} 
impuestas por el juez. A este respecto, cabe mencionar las siguientes: obligación de asistir con regularidad al centro docente correspondiente, si el menor está en edad de escolarización obligatoria, y acreditar ante el Juez dicha asistencia regular o justificar en su caso las ausencias, cuantas veces fuere requerido para ello; obligación de someterse a programas de tipo formativo, cultural, educativo, profesional, laboral, de educación sexual, de educación vial u otros similares; prohibición de acudir a determinados lugares, establecimientos o espectáculos; prohibición de ausentarse del lugar de residencia sin autorización judicial previa; obligación de residir en un lugar determinado; obligación de comparecer personalmente ante el juzgado de menores o profesional que se designe, para informar de las actividades realizadas y justificarlas; cualesquiera otras obligaciones que el juez, de oficio o a instancia del Ministerio Fiscal, estime convenientes para la reinserción social del sentenciado, siempre que no atenten contra su dignidad como persona.

La asistencia a un centro de día consiste en que los menores sujetos a esta medida residirán en su domicilio habitual y acudirán a un centro, plenamente integrado en la comunidad, a realizar actividades de apoyo, educativas, formativas, laborales o de ocio, a fin de mejorar su competencia social. En consecuencia, pretende proporcionar al menor un ambiente apropiado durante buena parte del día.

La convivencia con otra persona, familia o grupo educativo implica la convivencia del menor, durante el período de tiempo determinado por el juez, con otra persona, con una familia distinta a la suya o con un grupo educativo, adecuadamente seleccionados a fin de proporcionar al menor un ambiente de socialización positivo.

Las prestaciones en beneficio de la comunidad. Esta medida requiere el consentimiento del menor y conlleva la realización de una actividad no retribuida, que se tratará de relacionar con el bien jurídico afectado, en beneficio de la colectividad en su conjunto.

La realización de tareas socio-educativas entraña el desarrollo, sin internamiento ni libertad vigilada, de actividades concretas de contenido educativo dirigidas a facilitarle su reinserción social ${ }^{29}$.

La amonestación es un acto único realizado por el juez en el que se pretende hacerle entender al menor la gravedad de los hechos cometidos y las consecuencias que los mismos han tenido o podrían haber tenido, instándoles a que no vuelva a perpetrarlos en el futuro.

La prohibición de aproximarse o comunicarse con la víctima o con aquellos de sus familiares u otras personas que establezca el juez. Por un lado, esta medida disuadirá al menor de acercarse a ellos, en cualquier lugar donde se encuentren, así como a su domicilio, a su centro docente, a sus lugares de trabajo y a cualquier otro que sea frecuentado por ellos. Por otro lado, la prohibición de comunicarse con la víctima, o con aquellos de sus familiares u otras personas que determine el juez o tribunal, también imposibilitará que el menor establezca con ellas, por cualquier medio de comunicación o medio informático o telemático, contacto escrito, verbal o visual. En caso de que esta medida conllevase la imposibilidad del menor de seguir viviendo con sus padres, tutores o guardadores, el Ministerio Fiscal deberá remitir testimonio de los particulares a la entidad pública de protección del menor, la cual habrá de promover las medidas de

\footnotetext{
${ }^{29}$ Nos referimos, por ejemplo, a asistir a un curso de preparación de empleo, participar en actividades de animación sociocultural o en talleres de aprendizaje.
} 
protección apropiadas a las circunstancias de aquél, de acuerdo con lo previsto en la citada Ley Orgánica 1/1996, de 15 de enero, de Protección Jurídica del Menor.

La privación del permiso de conducir ciclomotores o vehículos a motor, o del derecho a obtenerlo, o de licencias administrativas para la caza o para el uso de cualquier tipo de armas. Esta medida podrá imponerse como accesoria en aquellos casos en los que el hecho cometido tenga relación con la actividad que efectúa el menor y que ésta necesite autorización administrativa.

La inhabilitación absoluta implica la privación definitiva de todos los honores, empleos y cargos públicos, así como la incapacidad para obtenerlos durante la duración de la medida y suele imponerse como accesoria en los casos de delito de terrorismo.

Habida cuenta de la amplia relación de medidas, cabe destacar que a la hora de escoger la adecuada debe partirse de un amplio criterio de flexibilidad debiendo de basarse la imposición de la medida en la valoración jurídica de los hechos y, muy especialmente, en la edad, las circunstancias familiares y sociales, en la personalidad y en el interés del menor. En definitiva, y a diferencia de lo que sucede con la jurisdicción de adultos, el juez de menores no está obligado a imponer una medida en atención al hecho cometido, sino que tendrá que realizar una valoración de las circunstancias enumeradas ${ }^{30}$.

Ahora bien, una vez acordadas estas medidas, es posible que el juez de menores las modifique, aun cuando ya se estén ejecutando. Así, resulta viable sustituir la medida por otra que entienda más apropiada para el menor de entre las que podría haber impuesto inicialmente a la infracción cometida. De igual modo, se puede reducir la duración de la medida durante el tiempo que el juez considere oportuno, teniendo en cuenta el informe del equipo técnico y dando audiencia previa al Ministerio Fiscal y al letrado del menor. Por último, cabe dejar sin efecto la medida impuesta dando por terminada la ejecución de ésta por estimarse que el tiempo cumplido resulta suficiente o cuando el menor declara su voluntad de conciliarse con la víctima durante la ejecución de la medida y ésta se lleve a cabo en los términos del artículo 19 de la LECrim $^{31}$.

Con todo y con ello, en los últimos años el número de medidas que se ejecutan ha aumentado, lo cual debe entenderse como positivo, toda vez que significa que las nuevas medidas incorporadas se adecuan no solo a la comisión de delitos, que igual habrían sido

\footnotetext{
${ }^{30}$ No obstante, hay supuestos en que el juez de menores se ve constreñido a imponer la medida de internamiento en régimen cerrado. Véase artículo 9.5 de la LO 5/2000: "Excepcionalmente, cuando los supuestos previstos en la regla anterior revistieran extrema gravedad, apreciada expresamente en la sentencia, el Juez habrá de imponer una medida de internamiento de régimen cerrado de uno a cinco años de duración, complementada sucesivamente por otra medida de libertad vigilada con asistencia educativa hasta un máximo de otros cinco años. Sólo podrá hacerse uso de lo dispuesto en los artículos 14 y 51.1 de esta Ley una vez transcurrido el primer año de cumplimiento efectivo de la medida de internamiento".

${ }^{31}$ Este precepto regula el sobreseimiento del expediente por conciliación o reparación entre el menor y la víctima.

En efecto, el menor puede reconocer los hechos y conformarse con la pena pedida. Puede, incluso reconociendo los hechos, discutir en juicio que la pena interesada sea la más apropiada, de acuerdo a sus circunstancias personales. De hecho, en el procedimiento de menores son numerosos los asuntos que se cierran sin necesidad de celebrar juicios, bien porque el Ministerio Fiscal desiste de la continuación del procedimiento, bien porque es alcanzada una conciliación con la víctima o bien porque se reconozcan los hechos y se produzca la conformidad.

Para un análisis más exhaustivo véase: VARELA GÓMEZ, B. J. (2018), "Mediación penal y procedimiento de menores", CASTILLEJO MANZANARES, R. (Dir.) y ALONSO SALGADO, C. (Coord.): Nuevos debates en relación a la mediación penal, civil y mercantil. Santiago de Compostela: Servicio de Publicaciones e Intercambio Científico, pp. 549 a 561.
} 
desjudicializados o corregidos con medidas de naturaleza diferente, sino también a las circunstancias personales del menor y a las del hecho cometido.

Por último, en cuanto a la posibilidad de introducir nuevas medidas ad futurum, cabe resaltar que se aprecia la ausencia de algunas medidas, como la multa ${ }^{32}$, la cual sólo tendría sentido cuando el menor dispusiese de medios propios, o la posibilidad de una medida de permanencia de semana para menores que, por ejemplo, hayan abandonado los estudios y dispongan de una ocupación laboral durante los fines de semana, con el propósito de compatibilizar la medida con su vida laboral.

\subsection{Soluciones extrajudiciales frente al acoso escolar: creación de programas de mediación en los centros escolares.}

\subsubsection{Cuestiones generales.}

Los centros educativos se convierten durante gran parte de la juventud en nuestra segunda casa, por lo que las aulas son, sin duda, uno de los lugares con mayor interacción que nos podemos encontrar, y es que cuenta con la combinación idónea para ello: personas de diferentes edades, de todas las culturas y con visiones totalmente individualizadas de la realidad, conviviendo diariamente.

A consecuencia de esta interacción, no es infrecuente que surjan problemas de distinta clase $^{33}$. A fin de reducirlos, en la medida de lo posible, y promover la convivencia pacífica en los centros educativos, se resalta la importancia de nuevos métodos de resolución de conflictos, concretamente, el mecanismo de la mediación ${ }^{34}$.

En el ámbito escolar este método "alternativo" 35 de solución de conflictos, es sumamente relevante, no sólo para restablecer la situación alterada, sino también, y de manera especial, para que las partes implicadas aprendan a enfrentarse a los problemas de forma constructiva, a asumir responsabilidades, a autocontrolarse o a tener como

\footnotetext{
${ }^{32}$ CEZON GONZALEZ, C. (2001), La nueva Ley Orgánica Reguladora de la Responsabilidad Penal de los Menores. Barcelona: Bosch, S.A., p. 54.

${ }^{33}$ De relación (por ejemplo, cualquier acto de violencia), de información (como pueden derivarse de los rumores), derivados de intereses o necesidades incompatibles, por preferencias, valores o creencias diferentes, o conflictos estructurales (tales como los debidos a la autoridad que pueda tener sobre los alumnos un profesor). FUNES LAPPONI, S. y SAINT-MEZARD, D. (2001), "Conflicto y resolución de conflictos escolares: La experiencia de mediación escolar en España”, XXIII Escuela del Consejo Educativo de Castilla y León, p. 5.

${ }^{34}$ A juicio de BOQUÉ TORREMORELL, el objetivo esencial de la creación de una red de mediación en el centro no consiste, como bien pudiera pensarse, en la eliminación de los conflictos que las personas de la comunidad educativa supuestamente generan. En puridad, lo que persigue la mediación no es otra cosa que crear vínculos de unión entre las familias, los alumnos, los docentes y demás miembros del entorno escolar. Y ello porque cuando se crea una red de estas características, la comunidad educativa puede hacer aflorar los conflictos sin temor alguno a que ello suponga un deterioro o un perjuicio para el centro (BOQUÉ TORREMORELL, M. C. (2004), "Mediación escolar: unidos ante el conflicto", Perspectiva CEP. Consejería de Educación de la Junta de Andalucía, 8, pp. 55-69).

${ }^{35}$ En este contexto, la alternatividad no hace referencia a la evitación de la vía judicial, dado que los conflictos escolares no suelen tener una gravedad tal que exija su judicialización, sino que es un método que trata de sustituir los castigos o medidas disciplinarias tradicionales que se imponen a los sujetos infractores en las aulas. Medidas éstas que adoptan habitualmente un matiz ejemplarizante, y que son sin duda la consecuencia evidente de la concepción negativa que se tiene del conflicto.
} 
herramienta el diálogo y la empatía. En definitiva, a poder adquirir "herramientas y habilidades aplicables en la vida futura" 36 .

\subsubsection{El proceso de normativización de la mediación escolar.}

La introducción de la mediación en la escuela tiene lugar por primera vez en Estados Unidos, en la década de los sesenta, gracias a la labor de distintos grupos religiosos y movimientos para la Educación para la Paz. No sería hasta años después cuando empezarían en España los primeros proyectos ${ }^{37}$, destacando el Centro de Resolución de Conflictos Gernika Gogoratuz, creado en los años noventa y que desarrolla programas de investigación y educación en colaboración con otras organizaciones ${ }^{38}$. Desde entonces, y teniendo en cuenta que el contexto internacional era favorable para ello ${ }^{39}$, proliferaron en distintas normativas las referencias a la mediación escolar, pero, si bien es cierto, no siempre de manera expresa.

Así las cosas, a nivel nacional, tras la modificación realizada por la Ley Orgánica 1/2004, de 28 de diciembre, de Medidas de Protección Integral contra la Violencia de Género, en la Ley Orgánica 8/1985, de 3 de julio, reguladora del derecho a la educación, se introduce dentro de los fines de la actividad educativa "La formación para la paz, la cooperación y la solidaridad entre los pueblos y para la prevención de conflictos y para la resolución pacífica de los mismos y no violencia en todos los ámbitos de la vida personal, familiar y social" -artículo 2-. Destaca también la posterior aprobación de la Ley 27/2005, de 30 de noviembre, de fomento de la educación y la cultura de paz. Entre otras medidas encaminadas a la pacificación de las relaciones en el ámbito educativo, esta norma recoge en su artículo 2.7 que corresponde al Gobierno "promover la formación especializada de hombres y mujeres en técnicas de resolución de conflictos, negociación $y$ mediación" $"$.

\footnotetext{
${ }^{36}$ PÉREZ CRESPO, M. J. (2002), "La Mediación escolar, proceso de suma de los modelos de intervención mediadora en la escuela: los programas de mediación escolar y la mediación social intercultural a su paso por instituciones educativas", Revista Educación y Futuro, p. 7.

${ }^{37}$ A la cabeza del desarrollo de los programas de mediación en este ámbito estuvieron las Comunidades Autónomas del País Vasco, Cataluña y Madrid.

${ }^{38}$ DE PRADA DE PRADO, J. y LÓPEZ GIL, J. A. (2008), "La mediación como estrategia de resolución de conflictos en el ámbito escolar", Documentación Social, pp. 99-116.

En efecto, se generaron un buen número de programas entre los cuales cabe destacar: Children's Creative Response to Conflict Program: los que primero introducen la mediación en las escuelas en Estados Unidos; Conflict Resolution Resources for School and Youth: este programa no solo ha sido el punto de partida de gran parte de la aplicación de programas de resolución de conflictos en el ámbito escolar, sino que también ha servido de modelo para aplicar iniciativas de mediación en la educación superior; Teaching Students to Be Peacemakers Program: uno de los objetivos fundamentales de este programa es crear una relación positiva entre los estudiantes; Educators for Social Responsability: entre otras finalidades, imparte formación al profesorado en técnicas de resolución de conflictos; Resolving Conflict Creatively Program: constituye un buen ejemplo de un programa basado en el desarrollo de un currículo de resolución de conflictos; Conflict Resolution Education Network: se crea la NAME (National

Association for Mediation in Education) y posteriormente se fusión con NIDR (National Institute for Dispute Resolution) y se convirtió en el que se denomina CREnet (Conflict Resolution Education Network), que redefine los objetivos de la anterior organización, más allá de la mediación en la escuela,

definiendo de modo más amplio la resolución de conflictos escolar (VIANA-ORTA, M. I. (2011), La mediación en el ámbito educativo en España. Estudio comparado entre Comunidades Autónomas. Valencia: Universidad de Valencia, pp. 93-95).

${ }^{39}$ En la Resolución 53/25, de noviembre de 1998 de las Naciones Unidas se declara la década de 2001 a 2010, como la Década Internacional para la Cultura de la Paz.

${ }^{40}$ VIANA-ORTA, M. I. (2014), "La mediación escolar en los planes y programas institucionales de convivencia en España”, Revista Complutense de Educación, vol. 25, núm. 2, pp. 271-291.
} 
Más tarde, aparece la Ley Orgánica 2/2006, de 3 de mayo, de Educación, todavía vigente, siguiendo esta línea, ya en su artículo 1 nos señala que uno de los principios que informará el sistema educativo español será "la educación para la prevención de conflictos y la resolución pacífica de los mismos, así como para la no violencia en todos los ámbitos de la vida personal, familiar y social, y en especial en el del acoso escolar" ${ }^{41}$. De otra parte, la Ley Orgánica 8/2013, de 9 de diciembre, para la mejora de la calidad educativa, entre otras modificaciones, introduce una Disposición adicional cuadragésima primera a la Ley Orgánica 2/2006, con el siguiente tenor literal "En el currículo de las diferentes etapas de la Educación Básica se tendrá en consideración el aprendizaje de la prevención y resolución pacífica de conflictos en todos los ámbitos de la vida personal, familiar y social, y de los valores que sustentan la democracia y los derechos humanos, que debe incluir en todo caso la prevención de la violencia de género y el estudio del Holocausto judío como hecho histórico". Como vemos, en estos últimos cuerpos legales que mencionamos, no se hace una alusión expresa a la mediación, pero estando incluida dentro de los métodos pacíficos de resolución de conflictos, no cabe sino entender, que está contemplada implícitamente.

Además, cabe mencionar, por un lado, los acuerdos de mejora de la convivencia escolar aprobados por el Ministerio de Educación ${ }^{42}$, y por el otro, las "Propuestas para un Pacto Social y Político por la Educación". En estas últimas, se recoge dentro de los objetivos de la educación para los cursos comprendidos entre 2010 y 2020, esta vez sí expresamente, la implantación de la mediación escolar en los centros educativos españoles ${ }^{43}$.

Por su parte, desde la perspectiva autonómica, las Comunidades Autónomas fueron materializando sus competencias en educación, elaborando sus propias leyes y estableciendo sus programas de convivencia ${ }^{44}$. Estos programas, que pueden estar orientados a cuatro fines distintos ${ }^{45}$, únicamente aluden de manera expresa a la mediación

\footnotetext{
${ }^{41}$ En un sentido muy similar, se pronuncia el artículo 2, que incluye dentro de los fines a conseguir, "la educación en el ejercicio de la tolerancia y de la libertad dentro de los principios democráticos de convivencia, así como en la prevención de conflictos y la resolución pacífica de los mismos".

Véanse también, en consonancia con ello, artículos como el $1.1 \mathrm{k}$ ); $2.1 \mathrm{c}) ; 13 \mathrm{e}$ ); $17 \mathrm{c}) ; 40.1 \mathrm{~d}$ ); etc. de la Ley Orgánica 2/2006. De igual modo, la Disposición adicional vigésimoprimera de esta Ley Orgánica contempla la posibilidad de que las Administraciones educativas aseguren "la escolarización inmediata de las alumnas o alumnos que se vean afectados por cambios de centro derivados de actos de violencia de género o acoso escolar. Igualmente, facilitarán que los centros educativos presten especial atención a dichos alumnos".

${ }^{42}$ Así, cabe mencionar el "Plan para la Promoción y Mejora de la Convivencia Escolar" y el "Plan Director para la Convivencia y la Seguridad Escolar".

${ }^{43}$ Dentro de la convivencia escolar y educación en valores, su propuesta número 58 alude a "Promover que las administraciones educativas, a partir de los datos obtenidos desde el Observatorio Estatal de la Convivencia, junto con los de diversas Comunidades Autónomas, elaboren propuestas, materiales de apoyo y actividades de formación que faciliten la elaboración en todos los centros de Planes de Convivencia que tengan en cuenta la diversidad cultural e ideológica, la igualdad entre hombres y mujeres, la mediación y la resolución pacifica de conflictos".

${ }^{44} \mathrm{Vid}$. http://www.mecd.gob.es/educacion-mecd/mc/convivencia-escolar/mapa-ccaa/normativa.html.

45 Pueden encaminarse a cambios en la organización escolar, en los que se tengan en cuenta a todos los miembros del centro; formación del profesorado; actividades para desarrollar en el aula (por ejemplo, trabajos en grupo, actividades de educación de sentimientos, en valores, etc.); o bien a la actuación específica frente a la violencia escolar existente. En esta cuarta categoría se encaja la mediación. DEL REY, R. y ORTEGA RUIZ, R. (2001), "Programas para la prevención de la violencia escolar en España, la respuesta de las Comunidades Autónomas", Revista Interuniversitaria de formación del profesorado, núm. 41, pp. 133-145.
} 
en el caso de Andalucía, Aragón, Asturias, Baleares, Canarias, Castilla-La Mancha, Cataluña, Extremadura, Galicia y Murcia ${ }^{46}$.

\section{El cine como recurso educativo para la explicación del sistema de responsabilidad penal del menor.}

En el contexto actual, si un estudiante del Grado en Derecho sólo recibe una formación estrictamente descriptiva de lo que es un ordenamiento jurídico, si únicamente aprende a interpretar las normas jurídicas en abstracto, despegadas del marco en el que se aplican, es decir, si los estudiantes no han tenido o no han comprendido todas estas variadas repercusiones en las personas, cabe estimar que tendrán un injustificable déficit como juristas.

En este sentido, el estudio del Derecho a través del cine adquiere un valor notable, pues pocos instrumentos son tan propicios para un análisis interdisciplinar como el cine, dado que normalmente en la narración fílmica se muestran los asuntos jurídicos de una forma similar a cómo estos se dan en la realidad, y en este sentido, aparecen con todas sus diversas y múltiples aristas y vinculaciones. Así, el Derecho en el cine puede explicarse brevemente, desde un punto de vista próximo a lo epistemológico, a partir de tres rasgos dependientes entre sí: primero, se trata de una forma de relato jurídico, o en otras palabras, se cuentan historias en las que predomina algún tema relacionado con el derecho -este caso, el régimen de la responsabilidad penal del menor-; segundo, se utilizan técnicas narrativas que, de una manera $\mathrm{u}$ otra, contienen argumentaciones jurídicas; y tercero, se pretende, en cierto sentido, o bien tratar directamente aspectos de la realidad relacionados con el Derecho en un sentido amplio, o llegar a suplantar la realidad a través de la ficción ${ }^{47}$.

La proyección de la película «Bullying» es viable en el marco de las sesiones interactivas de diversas materias incluidas en el Derecho procesal, tales como "Derecho proceso penal" del Grado en Derecho o "Delincuencia y Justicia juvenil" y "Proceso penal" del Grado en Criminología.

Esta práctica se puede desarrollar a lo largo de dos sesiones. En la primera, se procederá al visionado de la película en el aula. Y en la segunda sesión, cada alumno y alumna realizará por escrito un análisis del filme, incidiendo en las cuestiones procesales que hayan suscitado su interés y que hayan observado a lo largo del mismo, acerca de todo lo relativo a la responsabilidad penal que se deriva de los hechos cometidos por

\footnotetext{
${ }^{46}$ A modo de ejemplo, en Galicia, se aprueba la Ley 4/2011, de 30 de junio, de convivencia y participación de la comunidad educativa y, a posteriori, se promulga el Decreto $8 / 2015$, de 8 de enero, por el que se desarrolla aquella. Ambas normas recogen entre sus fines la resolución pacífica de los conflictos. Por un lado, el artículo 3 f) de la Ley señala: "Promover la resolución pacífica de los conflictos y fomentar valores, actitudes y prácticas que permitan mejorar el grado de aceptación y cumplimiento de las normas, avanzar en el respeto entre todos los miembros de la comunidad educativa y la mejora de la convivencia escolar"). Por otro lado, también el artículo 3 f) del Decreto dispone: "La promoción de la resolución pacífica de los conflictos y el fomento de valores, actitudes y prácticas que permitan mejorar el grado de aceptación y cumplimiento de las normas".

El artículo que más interés despierta de la Ley 4/2011 es el 20. Este precepto empieza haciendo una remisión al reglamento para determinar un procedimiento conciliado para la resolución de los conflictos de convivencia. Como se observa, no hace alusión directa a la mediación, de modo que dejaba la puerta abierta a otros procesos similares, siempre que encajaran en la categoría de "conciliados". Pero si tenemos presente, que posteriormente el Decreto de desarrollo reguló en su artículo 26 la mediación, entendemos que el legislador se decantó por este método de entre los posibles.

${ }^{47}$ RUIZ SANZ, M. (2010), "La enseñanza del Derecho a través del cine: implicaciones epistemológicas y metodológicas", Revista de Educación y Derecho, núm. 2, abril - septiembre.
} 
Nacho y los compañeros. Posteriormente, y de forma grupal, se abrirá un debate, en el que se pondrá en común la opinión que a cada uno le merece la película, pudiendo expresar valoraciones personales. Así, en la calificación que el docente haga de cada alumno se tendrá en cuenta, tanto el trabajo escrito, como su participación en el debate.

De esta manera, se permitirá identificar con claridad conceptos que habían sido explicados en clase y analizar cómo se ajustará a las disposiciones normativas y, en su caso, a la doctrina y jurisprudencia españolas. Y es que a través del visionado de esta película se pretende fomentar la capacidad de interpretar y analizar las normas aplicables a los supuestos de hecho que, sin ningún tipo de estructura jurídica, se van planteando en el argumento de la película. Y ello porque cada vez que tiene lugar un crimen perpetrado por menores se reabre y recrudece el debate en torno al sistema de justicia juvenil implantado en España por la Ley Orgánica 5/2000.

\section{Conclusiones.}

El acoso es una verdadera lacra que debería ser eliminada de forma radical, porque ninguna persona debe ser sometida a hostigamiento, y la sociedad debe generar recursos efectivos y de aplicación inmediata para impedir estas conductas ajenas a la legalidad. Si este problema resulta alarmante, todavía se agrava más cuando hablamos del acoso a menores, debido a que estos no suelen disponer de estrategias para hacer frente al acoso: en unos casos desconocen que pueden resolver su problema y en otras ocasiones no saben cómo hacerlo. La nota común en ambos casos es que puede causárseles daños de difícil reparación. Por eso, es imprescindible disponer de respuestas por parte del ordenamiento jurídico, pero también es fundamental actuar en un nivel preventivo, esto es, educando, informando, proporcionando estrategias dirigidas a resolver los conflictos, trabajando en potenciar la reflexión, la tolerancia, el respeto o la empatía.

En definitiva, resulta esencial tender puentes entre los tres ámbitos de socialización: familia, escuela y entorno social, pues únicamente desde la interconexión y coordinación entre todos los agentes socializadores que van apareciendo durante la vida de los menores se garantiza un proceso educativo adecuado $\mathrm{y}$, por consiguiente, una prevención apropiada del problema analizado48.

Ahora bien, un aspecto acerca del que existe un consenso unánime es la forma de abordar el fenómeno desde una posición de análisis e investigación del problema de la violencia escolar y sus características. $\mathrm{Y}$ en este camino, la utilización del cine como recurso educativo para el proceso de enseñanza-aprendizaje del Derecho, nos permite profundizar y constatar las posibles debilidades y fortalezas que presenta el sistema de justicia penal de menores. Y es que desde una óptica pro-innovación, la utilización del cine como recurso educativo para el aprendizaje del Derecho resulta más que común, toda vez que en los últimos años se advierte en la población más joven de nuestro país una creciente querencia hacia determinados productos audiovisuales.

\footnotetext{
${ }^{48}$ En este sentido, cabe referirse al Centro Nacional de Innovación e Investigación Educativa (CNIIE) que, como unidad perteneciente al Ministerio de Educación Cultura y Deporte, es consciente de la problemática social relacionada con la convivencia escolar, por lo que promueve el desarrollo de actuaciones específicas para la prevención de la violencia en el ámbito de la escolarización ordinaria. A este respecto, el CNIIE ha elaborado la campaña "Se buscan héroes y heroínas sin antifaz", dirigido a sensibilizar a la comunidad educativa acerca de la importancia de la prevención, detección e impacto de los incidentes de acoso, ciberacoso y violencia, así como del apoyo a las víctimas de violencia escolar incluyendo en el repositorio de documentos y recursos para la mejora de la convivencia escolar materiales relacionados con el apoyo a las víctimas de violencia escolar y difundiéndolos en los centros.
} 
En efecto, el visionado de la película «Bullying» puede ser el punto de partida perfecto para abordar diversas cuestiones de interés jurídico. De este modo, nos permitirá acercarnos al problema del acoso escolar y la responsabilidad penal del menor, así como también reflexionar sobre el papel que la sociedad juega en esta problemática, teniendo en cuenta que algunas de las trabas, dificultades y exclusiones a las que se han visto sometidos numerosos menores, por desgracia, todavía perviven hoy en día.

En definitiva, con este recurso educativo se pretende profundizar en la capacidad analítica del alumnado en la convicción de que la visibilización práctica de determinadas cuestiones favorezcan su motivación y comprensión de los contenidos de la materia. De esta forma se reta al alumnado con algo que les atrae, que les emociona, que les engancha $\mathrm{y}$, sobre todo, que no encuentra respaldo en la red.

\section{Bibliografía.}

- ÁLVAREZ GONZÁLEZ, E. M. (2015), "El cine como recurso docente aplicable a la enseñanza del derecho administrativo", REJIE: Revista Jurídica de Investigación e Innovación Educativa, núm. 11, enero, pp. 97-108.

- BERROCAL LANZAROT, A. I. (2010), "La comunidad educativa ante el acoso escolar o bullying. La responsabilidad civil de los centros docentes", Diario La Ley, núm. 7359, año XXXI, 10 de marzo, Ref. D-79, Editorial La Ley.

- BOQUÉ TORREMORELL, M. C. (2004), “Mediación escolar: unidos ante el conflicto", Perspectiva CEP, núm. 8, pp. 55-69.

- CASAL OTERO, L. (2019), "La innovación educativa en la educación superior", en OTERO CRESPO, M., ALONSO SALGADO, C. (Dirs.), VALIÑO CES, A. Y RODRÍGUEZ ÁlVAREZ, A. (Coords.), Investigación y Docencia en Derecho: nuevas perspectivas. A Coruña: Colex.

- CASTILLEJO MANZANARES, C. (2017), "La mediación en el ámbito educativo", en CASTILLEJO MANZANARES, R. (Dir.), ALONSO SALGADO, C. y VALIÑO CES, A. (Coords.): La mediación a examen: experiencias innovadoras y pluralidad de enfoques. Santiago de Compostela: Servicio de Publicaciones e Intercambio Científico de la Universidad de Santiago de Compostela.

- CEZON GONZALEZ, C. (2001), La nueva Ley Orgánica Reguladora de la Responsabilidad Penal de los Menores. Barcelona: Bosch, S.A.

- DE PRADA DE PRADO, J. y LÓPEZ GIL, J. A. (2008), "La mediación como estrategia de resolución de conflictos en el ámbito escolar", Documentación Social, pp. 99-116.

- DEL REY, R. y ORTEGA RUIZ, R. (2001), "Programas para la prevención de la violencia escolar en España, la respuesta de las Comunidades Autónomas", Revista Interuniversitaria de formación del profesorado, núm. 41, pp. 133-145. 
- FERRO VEIGA, J. M. (2012), Bulling o acoso escolar. La respuesta jurídico-legal. Jaén: Formación Alcalá.

- FRANCO GARCÍA, M. A. (2016), "Los nuevos criterios atributivos de responsabilidad patrimonial en el acoso escolar entre alumnos", Actualidad administrativa, núm. 4.

- FUNES LAPPONI, S. y SAINT-MEZARD, D. (2001), “Conflicto y resolución de conflictos escolares: La experiencia de mediación escolar en España”, XXIII Escuela del Consejo Educativo de Castilla y León.

- GONZÁlEZ PÉREZ, J. y SANTIUSTE BERMEJO, V. (2004), "Los conflictos entre alumnos: características e intervención para una sociedad democrática", Revista de Psicología General y Aplicada, núm. 57 (3).

- JIMÉNEZ DÍAZ, M. J. (2015), “Algunas reflexiones sobre la responsabilidad penal de los menores", Revista Electrónica de Ciencia Penal y Criminología (en línea), núm. 17-19, pp. 1-36.

- MAGRO SERVET, V. (2014), “Otras formas de violencia sobre los menores. El acoso escolar", La Ley Derecho de familia, 12 de noviembre, Editorial La Ley.

- MONTERO HERNANZ, T. y DE VICENTE MARTÍNEZ, R. (2016), Derechos de las personas a las que se aplique la ley orgánica reguladora de la responsabilidad penal de los menores. Valencia: Tirant lo Blanch.

- PÉREZ CRESPO, M. J. (2002), “La Mediación escolar, proceso de suma de los modelos de intervención mediadora en la escuela: los programas de mediación escolar y la mediación social intercultural a su paso por instituciones educativas", Revista Educación y Futuro.

- PÉREZ MACHÍO, A. I. (2007), "Tratamento xurídico-penal do bullying”, en XUNTA DE GALICIA, Menores e xuventude: novos retos. Cambados (Pontevedra): Consellería de Presidencia, Academia Gallega de Seguridad Pública.

- PÉREZ MARTELL, R. (2012), "El bullying (acoso escolar) y el cyberbullying: prevención y soluciones desde la vía judicial y las extrajudiciales", Diario La Ley, núm. 7978, Sección Doctrina, 4 de diciembre, Ref. D-431, Editorial La Ley.

- POLVOROSA ROMERO, S. (2017), "El acoso escolar llevado a internet: los smartphone y smartwatch", La Ley Derecho de familia, núm. 14.

- PRESNO LINERA, M. A. y RIVAYA, B. (2006), Una introducción cinematográfica al Derecho. Valencia: Tirant lo Blanch.

- RODRÍGUEZ AMUNÁTEGUI, C. (2007), La responsabilidad civil derivada del bullying y otros delitos de los menores de edad. Madrid: Ediciones del Laberinto, S.L. 
- RUIZ SANZ, M. (2010), “La enseñanza del Derecho a través del cine: implicaciones epistemológicas y metodológicas”, Revista de Educación y Derecho, núm. 2, abril septiembre.

- VALIÑO CES, A. (2018), "Material didáctico sobre la película 'Bullying'”, Revista electrónica Proyecto DeCine, 12 de noviembre. Disponible en:

https://proyectodecine.wordpress.com/2018/11/12/materia-didactico-abierto-

bullying/.

- VARELA GÓMEZ, B. J. (2018), "Mediación penal y procedimiento de menores", CASTILLEJO MANZANARES, R. (Dir.) y ALONSO SALGADO, C. (Coord.): Nuevos debates en relación a la mediación penal, civil y mercantil. Santiago de Compostela: Servicio de Publicaciones e Intercambio Científico.

- VIANA-ORTA, M. I. (2011), La mediación en el ámbito educativo en España. Estudio comparado entre Comunidades Autónomas. Valencia: Universidad de Valencia.

- VIANA-ORTA, M. I. (2014), “La mediación escolar en los planes y programas institucionales de convivencia en España", Revista Complutense de Educación, vol. 25, núm. 2, pp. 271-291.

- ZABAY, M. y CASADO, A. (2018), Todos contra el bullying. Claves para detectar, evitar y solucionar el acoso escolar. Barcelona: Alienta Editorial. 